SAUERS, Michael P. Searching 2.0. London: Facet Publishing. 2009. 350 pages. ISBN: 9781856046299 . $£ 44.95$.

Searching 2.0 is aimed at developing user awareness of the vast number of tools that can provide information from the web. Looking specifically at Web 2.0 tools, Michael P Sauers considers the uses of social bookmarking and wikipedia and provides guidance on improving your internet browsers' search capability. Throughout the book, he guides readers through media, local, desktop and even historical searches and provides practical exercises to support the reader to use the tools purposefully. This book is predominately aimed at anyone who considers themselves to have little knowledge of search tools beyond Google and would like to know more about other web tools that support information searches. With library and in particular, reference staff, a target audience, Sauers opens the book with an enthusiastic look at the usefulness of bookmark tool, del.ic.ious, and provides a visual step by step to getting started with tagging and sharing bookmarks, making a conscious effort to stay away from techno speak and to relate the "relationship [of the tools] to librarians and searching" (p7).

Sauers places emphasis on the participative and collaborative nature of Web 2.0 and the style of this book supports staff development with its simple and highly graphical approach to getting started with some of the more popular Web 2.0 tools. Screen captures are used to support the reader and Sauers pedagogically underpins practical instruction by relating the theory to practice.

While the book is designed to be worked through from start to finish, many readers will find it just as easy to dip into areas of specific interest. Each chapter is written with an introduction that is scenario related; in Chapter 7, Sauers discusses how librarians are not comfortable searching for content in print material via the web and then builds the chapter around Google Book Search with practical examples of what can be done using this tool, in a way to tempt those that may not be fully convinced. In Chapter 5, Searching for Media, he encourages readers to try searching for media instead of creating it, with a step by step guide on how to search Flickr for images. He suggests searching Flickr for photos of your library with the challenge that he was surprised at how often "librarians insist that there weren't any photos of their library online" (p138). I couldn't resist testing that theory out and he was right, my university library is on there! Chapter 8, Searching the Past, will be of interest to those that get frustrated by finding that pages on the web that have been updated without crucial information. His final chapter, Data Visualisation - The Future of Search, is an interesting look at some of the tools that may influence searches in the future, using the theory that there may be so much data that there will be a real need for graphical representation of search results. His introduction to 'literature map' and 'kartoo' cloud searches is intriguing and the image of a world map representing number of Olympic medals (p320) is an excellent way of demonstrating what future search results could look like.

Sauers is skilled at simplifying and raising awareness of the uses of Web 2.0 tools and technologies from a librarian's perspective. He provides a visual and userfriendly practical guide that will enable and possibly encourage anyone with an interest in this area. The pace of change that occurs with Web 2.0 tools will 
possibly render this book outdated in a very short time, because of the use of screen shots, which is unfortunate as the visual nature of this book adds to its simplicity. That said, much of the staff development aspect of the material in this book is already available on the web, in various guises and usually linked to the related software, the advantage of using this book is that Sauers clearly demonstrates his knowledge on how to underpin the practical tools with theoretical and practical knowledge, something that is not likely to become outdated.

\section{Rachel Fitzgerald}

Learning Technology Manager

University of Northampton

rachel.fitzgerald@northampton.ac.uk 